\title{
Genetic analysis of HLA class II alleles and susceptibility to Type 1 (insulin-dependent) diabetes mellitus in Japanese subjects
}

\author{
T. Awata ${ }^{1}$, T. Kuzuya ${ }^{1}$, A.Matsuda ${ }^{1}$, Y.Iwamoto ${ }^{1}$ and Y. Kanazawa ${ }^{2}$ \\ ${ }^{1}$ Division of Endocrinology and Metabolism, Jichi Medical School, Tochigi, ${ }^{2}$ Omiya Medical Center, Jichi Medical School, Omiya, Japan
}

\begin{abstract}
Summary. Although HLA-DQB1 alleles encoding aspartic acid at position 57 (Asp-57) are protective against Type 1 (insulin-dependent) diabetes mellitus in Caucasians, most Japanese Type 1 diabetic patients carry at least one Asp-57 DQB1 allele. We analysed the DRB1, DQA1 and DQB1 genes of 99 Japanese patients and 86 control subjects with polymerase chain reaction and sequence-specific oligonucleotide hybridization. We found that (1) the DQA1*0301 allele was significantly increased in Type 1 diabetic patients (RR 7.8, pc <0.0001); (2) the DRB1*0405 (Dw15) allele, which is a subtype of DR4 haplotype, was significantly in-
\end{abstract}

creased in DR4-positive patients $(R R 12.0, p c<0.001)$; and (3) although the DRw8-DQw8 haplotype was positively associated with Type 1 diabetes, the DRB1*0406-DQw8 haplotype was decreased in the diabetic patients. These data indicate that DRB1 and DQA1 genes also confer susceptibility to Type 1 diabetes in Japanese.

Key words: Human leucocyte antigen (HLA), gene, susceptibility, Type 1 (insulin-dependent) diabetes mellitus, Japanese.
Type 1 (insulin-dependent) diabetes mellitus is initiated by the selective autoimmune destruction of pancreatic Beta cells, and both genetic and environmental factors contribute to the development of the disease [1]. Associations with the HLA antigens have been reported since 1973 [2]; DR3 and DR4 are positively and DR2 is negatively associated with Type 1 diabetes in Caucasians [3], and DR4 and DR9 are positively and DR2 is negatively associated with the disease in Japanese [4-6].

In recent years, studies at the gene level have elucidated the HLA associations more precisely. Todd et al. proposed a hypothesis (Asp-57 hypothesis) that the amino acid at position 57 of DQ $\beta$ chain (DQB1) contributes to disease susceptibility; aspartic acid at DQB1-57 protects against Type 1 diabetes in Caucasians [7]. Horn et al. also pointed out the correlation of the amino acid at DQB1-57 with susceptibility to Type 1 diabetes [8]. The study of Caucasian families supported this hypothesis [9]. According to a model of HLA class II molecule structure [10], position 57 of DQB1 is located in a important position of the molecule which possibly affects the antigen binding and T-cell recognition, so that the charge of this amino acid may contribute to the autoimmune process leading to the development of Type 1 diabetes.

However, several exceptions to the Asp-57 hypothesis have been reported. The DR7-DQw2 haplotype is not as- sociated with Type 1 diabetes in Caucasians, whereas it is positively associated with the disease in Black populations. This distinction is thought to be due to the DQ $\alpha$ (DQA1) locus difference, DQA $1 * 0201$ in Caucasians and DQA1*0301 in Black populations [11]. The contribution of DQA1 genes in Caucasian patients was also reported by Khalil et al. [12]. Moreover, among the DR4-DQw8 haplotype, only the DRB1*0401(Dw4) and DRB1*0402 (Dw10) subtypes are positively associated with Type 1 diabetes. As the DR4 subtypes are determined by the DR $\beta$ (DRB1) genes, the DRB1 locus is thought to be involved in the DR4-associated susceptibility [13].

We have previously reported that, in Japanese subjects, the major susceptibility haplotypes to Type 1 diabetes are DR4-DQw4 and DR9-DQw9, both of which carry Asp at DQB1-57 [14]. The Asp-57 hypothesis, therefore, does not accommodate Japanese populations. Similar results have also been reported by other groups [15-18]. In this study, in order to to clarify the susceptibility genes to Type 1 diabetes in Japanese, we analysed the DRB1, DQA1 and DQB1 alleles, haplotypes and genotypes in 99 Japanese diabetic patients and 86 nondiabetic subjects. In addition to the contribution of DQA1 genes as suggested by previous studies $[16,18]$, we found that DRB1 genes also contributed to Type 1 diabetes in Japanese. 
Table 1. Sequences of oligonucleotide probes

\begin{tabular}{|c|c|c|}
\hline Sequence $\left(5^{\prime} \rightarrow 3^{\prime}\right)$ & Position & Allele \\
\hline GGAGCAGAAGCGGGCCGCG & DRB1:68-74 & DRB1 $* 0401$ \\
\hline GAAGACGAGCGGGCCGCG & DRB1:69-74 & DRB1 ${ }^{*} 0402$ \\
\hline GGTGTCCACCTCGGCCCGCC & DRB1:71-77 & DRB1*0403,0406 \\
\hline GAGCAGAGGCGGGCCGCG & DRB1:69-74 & DRB1*0404,0405 \\
\hline GGCCTAGCGCCGAGTACT & DRB1:55-61 & DRB1*0405 \\
\hline TATCACCAAGAGGAGTCCGT & DRB1:32-38 & DRB1*0406 \\
\hline GGCCTGATGCCGAGTACT & DRB1:55-61 & DRB1 $* 0401,0402,0403,0404,0406$ \\
\hline TTCAGCAAATTTGGAGGTT & DQA1:51-57 & DQA1 $* 0101,0102,0103$ \\
\hline TTCCACAGACTTAGATTTG & DQA1:51-57 & DQA1*0201 \\
\hline TTCCGCAGATTTAGAAGAT & DQA1:51-57 & DQA1*0301 \\
\hline TGTTTGCCTGTTCTCAGAC & DQA1:47-53 & DQA1*0401,0501,0601 \\
\hline TCTGGCCAGTTCACCCAT & DQA1:22-27 & DQA1 $* 0103,0201,0601$ \\
\hline TCTGGCCAGTACACCCAT & DQA1:22-27 & DQA1*0101,0102,0401,0501 \\
\hline GGAGATGAGGAGTTCTAC & DQA1:31-36 & DQA1*0101 \\
\hline GGAGATGAGCAGTTCTAC & DQA1:31-36 & DQA1*0102,0103,0501 \\
\hline CTGGAGAAGAAGGAGACT & DQA1:39-44 & DQA $1 * 0103$ \\
\hline ATCGCTGTGACAAAACACAAC & DQA1:66-72 & DQA1 $* 0401,0601$ \\
\hline ACCTTGAACAGTCTGATTAA & DQA1:72-77 & DQA1*0501 \\
\hline TACTCGGCAACAGGCCGCC & DQB1:54-60 & DQB1*0501,0604 \\
\hline GGCCTGATGCCGAGTACT & DQB1:55-61 & DQB1 $* 0602,0603$ \\
\hline GCGGCCTGACGCCGAGTAC & DOB1:54-60 & DQB1*0503,0601 \\
\hline GGCCTAGCGCCGAGTACT & DQB1:55-61 & $\mathrm{DQB} 1 * 0502$ \\
\hline GCTGGGGCTGCCTGCCG & DQB1:52-58 & $\mathrm{DQB} 1 * 0201$ \\
\hline TCGGCGTCAGGCGGCCCCA & DQB1:53-59 & $\mathrm{DQB} 1 * 0301,0303$ \\
\hline GGCCGCCTGCCGCCGAG & DQB1:54-59 & DQB1 $* 0302$ \\
\hline TCGGCGTCAAGCCGCCCCA & DQB1:53-59 & DQB1*0401,0402 \\
\hline GGGACCGAGCTCGTGCG & DQB1:20-25 & DQB1 0401 \\
\hline GGGACCGAGCGCGTGCG & DQB1:20-25 & DQB1 $* 0402$ \\
\hline CGTGCGTTATGTGACCA & DQB1:23-29 & DQB1*0601,0301 \\
\hline CGTGCGGGGTGTGACCA & DQB1:23-29 & DQB1 $* 0501,0502,0503,0401,0402$ \\
\hline CGTGCGTCTTGTGACCA & DQB1:23-29 & DQB1 $* 0602,0302,0303$ \\
\hline CGTGCGTCTTGTAACCA & DQB1:23-29 & DQB1 $* 0603,0604$ \\
\hline
\end{tabular}

\section{Subjects and methods}

\section{Subjects}

Ninety-nine unrelated Type 1 diabetic patients were studied, of which 86 were patients attending Jichi Medical School Hospital and blood samples of 13 patients were kindly offered by Dr. S. Amemiya, Department of Pediatrics, Yamanashi Medical College. The control subjects were 86 apparently healthy unrelated Japanese. Among these two groups, 69 patients and 79 non-diabetic subjects had been analysed for DQB1 genes previously [14]. Thirty-five patients were male, and sixty-four patients were female; the mean age at onset of diabetes was 26.4 years (range: 3 months to 64 years). The diagnosis of Type 1 diabetes was defined by both clinical features and laboratory data. We used serum and urinary $C$-peptide values to define insulin dependency. When the serum $C$-peptide value was less than $1 \mathrm{ng} / \mathrm{ml}$ (postprandial or after i. v. glucagon) and the urinary C-peptide value was less than $20 \mu \mathrm{g} / \mathrm{day}$, the patient was judged to be insulin-dependent. All subjects were previously serologically typed for $\mathrm{DR}$ antigens by the microcytotoxicity test.

\section{HLA genotyping}

HLA class II genes (DRB1, DQA1, DQB1) were analysed by the methods of polymerase chain reaction (PCR) and sequence-specific oligonucleotide (SSO) hybridization as described previously [14]. Genomic DNA (1 $\mu \mathrm{g})$, extracted from peripheral blood, was subjected to PCR to amplify the second exon coding the polymorphic first domain. Oligonucleotide primers were DR4/337C (5'TCTTGGAGCAGGTTAAACA3'), GH46E (5'CCGAATTCTTCGTG-
TCCCCACAGCACG3') and GH50 (5'CTCCCCAACCCCGTAGTTGTGTCTGCA3') for the DRB1 alleles; GH26P (5'GTGCTGCAGGTGTAAACTTGTACCAGT3') and GH27E (5'CAC GAATTCGGTAGCAGCGGTAGAGTTG3') for the DQA1 alleles; and GH28E (5'CTCGAATTCGCATGTGCTACTTCACCAACG3') and GH29 (5'GAGCTGCAGGTAGTTGTGTCTG$\mathrm{CACAC3}^{\prime}$ ) for the DQB1 alleles. PCR-amplified product (4-10 $\mu$ ) was dot-blotted onto nylon membrane. After fixation of DNA, the membrane was prehybridized at $42^{\circ} \mathrm{C}$ for more than $2 \mathrm{~h}$ in a solution of $5 \times \mathrm{SSPE}(0.75 \mathrm{~mol} / 1 \mathrm{NaCl}, 5 \mathrm{mmol} / \mathrm{l} \mathrm{EDTA}, 50 \mathrm{mmol} / 1$ sodium phosphate, $\mathrm{pH} 7.4), 5 \times$ Denhardt's solution $(0.1 \%$ bovine serum albumin, $0.1 \%$ Ficoll type $400,0.1 \%$ polyvinylpyrrolidone), $0.5 \%$ sodium dodecyl sulphate, and $20 \mu \mathrm{g} / \mathrm{ml}$ denatured salmon sperm DNA. The membrane was then hybridized at $42^{\circ} \mathrm{C}$ for more than $16 \mathrm{~h}$ with $\left[\gamma^{32} \mathrm{P}\right] \mathrm{ATP}$ end-labelled oligonucleotide probe (labelled by T4 polynucleotide kinase) in the same solution with prehybridization. Membrane was first washed twice in $6 \times \mathrm{SSC}(0.9 \mathrm{~mol} / 1 \mathrm{NaCl}$, $0.09 \mathrm{~mol} / \mathrm{l}$ sodium citrate) $/ 0.1 \% \mathrm{SDS}$ at room temperature for $10 \mathrm{~min}$ and then for $30 \mathrm{~min}$ at melting temperature. Occasionally, washing solution was substituted by $3 \mathrm{~mol} / \mathrm{l}$ tetramethylammonium chloride solution ( $3 \mathrm{~mol} / \mathrm{l}$ tetramethylammonium chloride, $50 \mathrm{mmol} / 1$ Tris-HCl, $\mathrm{pH} 7.4,2 \mathrm{mmol} / 1$ EDTA, $0.3 \%$ SDS). The membrane was exposed to Fuji RX film for several hours at $-70^{\circ} \mathrm{C}$ for autoradiography. The sequences of SSO probes used in this study are shown in Table 1. After DR4-specific PCR using DR4/337C and GH50, the subtypes of DR4 were distinguished by SSO probes of DRB1. To distinguish the DRB1*0404 allele from the DRB1*0405 allele, we used the probe which does not hybridize with the DRB1*0405 allele. The eight DQA1 alleles and the twelve DQB1 alleles were distinguished in this study. The $\mathrm{DOB1} 0602,0603$ probe and DQB1*0502 probe (Table 1) were used also to analyse position 57 of DRw8-associated DRB1 chain (see Discussion). 
Table 2. Frequencies of DR4 alleles in DR4-positive Japanese Type 1 (insulin-dependent) diabetic patients and control subjects

\begin{tabular}{lcccl}
\hline & $\begin{array}{l}\text { Patients } \\
(n=59) \\
n(\%)\end{array}$ & $\begin{array}{l}\text { Control } \\
\text { subjects } \\
(n=33) \\
n(\%)\end{array}$ & $R R$ & $\begin{array}{l}p c \\
\text { value }\end{array}$ \\
\hline DRB1*0401(Dw4) & $0(0)$ & $0(0)$ & - & NS \\
DRB1*0402(Dw10) & $0(0)$ & $0(0)$ & - & NS \\
DRB1*0403(Dw13) & $5(8.5)$ & $9(27.3)$ & 0.26 & $\mathrm{NS}^{\mathrm{a}}$ \\
DRB1*0404(Dw14) & $0(0)$ & $2(6.1)$ & 0.11 & $\mathrm{NS}^{\circ}$ \\
DRB1*0405(Dw15) & $56(94.9)$ & $19(57.6)$ & 12.0 & $<0.001$ \\
DRB1*0406(DwKT2) & $1(1.7)$ & $6(18.2)$ & 0.11 & $\mathrm{NS}^{\mathrm{a}}$ \\
\hline
\end{tabular}

${ }^{\mathrm{a}} p<0.05$ (uncorrected)

\section{Statistical analysis}

Differences were assessed by the Fisher's exact probability test. Corrected $p$ values $(p c)$ were calculated by multiplying the $p$ value by the number of alleles or genotypes, and level of significance was $p c<0.05$. Relative risks $(R R)$ were calculated with the formula of Haldane: $\left[\left(2 n_{31}+1\right)\left(2 n_{22}+1\right)\right] /\left[\left(2 n_{12}+1\right)\left(2 n_{21}+1\right)\right]$. Expected values of genotypes were calculated from gene frequencies. Gene frequencies were calculated with the formula $1-\sqrt{(1-t)}$, where $t$ is the observed allele frequency. The significance of deviations from HardyWeinberg equilibrium was assessed by the $\chi^{2}$ test.

\section{Results}

\section{Frequencies of DRB1 alleles}

In agreement with previous studies [4-6, 14], DR4 and DR9 were increased and DR2 and DRw11 were decreased in Type 1 diabetic patients compared with the control subjects (DR4 $59.6 \%$ vs $38.4 \%$, DR9 $51.5 \%$ vs $33.7 \%$, DR $23.2 \%$ vs $36.0 \%$, and DRw1 $10 \%$ vs $10.5 \%$ ). Table 2 shows the frequencies of the DR4 subtypes. The DR4 haplotypes is divided into subtypes DRB $1 * 0401$ (Dw4), DRB1*0402(Dw10), DRB1*0403(Dw13), DRB1 *0404(Dw14), DRB1*0405(Dw15) and DRB1*0406 (DwKT2). Among these, DRB1*0405 and DRB1 *0406 are rare in Caucasians. Of DR4-positive subjects, DRB $1 * 0405$ was significantly $(p c<0.001)$ increased in Type 1 diabetic patients compared with the control subjects $(94.9 \%$ vs $57.6 \%, R R 12.0)$, while DRB $1 * 0403$, DRB1 $* 0404$ and DRB1*0406 were decreased. None of the Japanese patients or control subjects had DRB ${ }^{*} 0401$ or DRB $1 * 0402$.

\section{Frequencies of DQA1 alleles and DQB1 alleles}

Table 3 shows the frequencies of DQA1 alleles. DQA1*0301 was significantly increased in the patients (93.9\% vs $65.1 \%, R R 7.8$ ), and DQA $1 * 0501$ was significantly decreased. DQA $1 * 0102$ and DQA1*0103 were not significantly decreased in the patients. Table 4 shows the frequencies of DQB 1 alleles. DQB $1 * 0401$ was significantly increased in the patients. DQB $1 * 0303$ was not significantly increased in the patients. DQB1*0402, which was usually found on the DRw8-DQw4 haplotype, was slightly increased in the patients. DQB1*0601, DQB1*0602 and DQB1*0301 were significantly decreased in the patients.
Negative association of DQB1*0602 was most distinct; only one patient had DQB1*0602 allele. DQB1*0302(3.2) was not significantly increased in the patients.

\section{Frequencies of probable haplotypes}

As the DR genes and the DQ genes are closely located on chromosome 6 , the alleles of DR and DQ are tightly linked [19]. Therefore, in most cases, we could assign probable DRB1-DQA1-DQB1 haplotypes of individuals. Table 5 show the frequencies of probable haplotypes. Major susceptibility haplotypes were DQB1*0405DQA1*0301-DQB1*0401 [DR4(Dw15)-DQw4] and DR9-DQA1*0301-DQB1*0303 [DR9-DQw9], which were observed in about half of the patients. Further, DRw8-DQA1*0301-DQB1*0302 [DRw8-DQw8], which is a Japanese-specific haplotype, was significantly increased in the patients. Negative associations were observed in DR2-DQA1*0102-DQB1*0601, DR2DQA1*0102-DQB1*0602 [DR2(Dw12)-DQw6] and DRw11-DQA1*0501-D QB1*0301 [DRw11-DQw7]. It was noted that DQB1*0406-DQA1*0301-DQB1*0302 [DR4 (DwKT2)-DQw8], was not increased in the patients.

\section{Genotype frequencies}

Table 6 shows the observed and expected genotype frequencies. Type 1 diabetic patients of this study deviate significantly from the Hardy-Weinberg equilibrium $\left(\chi^{2}=20.28, d f=10, p<0.05\right)$. The observed frequency of [DR4(Dw15)-DQw4]/[DR9-DQw9] heterozygotes was smaller than expected. In contrast, heterozygotes of [DR4(Dw15)-DQw4]/[DRw8-DQw8] and [DR4(Dw15)DQw4]/[DRw13-DQw6] were more frequent than expected.

\section{Discussion}

Since most Japanese patients with Type 1 diabetes carry Asp-57 DQB1 allele, the Asp-57 hypothesis [7] does not accommodate this racial group. The major susceptibility haplotypes found in Japanese patients were DR4(Dw15)-

Table 3. Frequencies of HLA-DQA1 alleles in Japanese Type 1 (insulin-dependent) diabetic patients and control subjects

\begin{tabular}{lccll}
\hline & $\begin{array}{l}\text { Patients } \\
(n=99) \\
n(\%)\end{array}$ & $\begin{array}{l}\text { Control } \\
\text { subjects } \\
(n=86) \\
n(\%)\end{array}$ & $R R$ & $\begin{array}{l}p c \\
\text { value }\end{array}$ \\
\hline DQA1*0101 & $9(9.1)$ & $16(18.6)$ & 0.45 & $\mathrm{NS}$ \\
DQA1*0102 & $26(26.3)$ & $40(46.5)$ & 0.41 & $\mathrm{NS}^{\mathrm{a}}$ \\
DQA1*0103 & $4(4.0)$ & $10(11.6)$ & 0.34 & $\mathrm{NS}$ \\
DQA1*0201 & $1(1.0)$ & $1(1.2)$ & 0.87 & $\mathrm{NS}$ \\
DQA1*0301 & $93(93.9)$ & $56(65.1)$ & 7.8 & $<0.0001$ \\
DQA1*0401 & $9(9.1)$ & $4(4.7)$ & 1.9 & $\mathrm{NS}$ \\
DQA1*0501 & $1(1.0)$ & $14(16.3)$ & 0.076 & $<0.01$ \\
DQA1*0601 & $0(0)$ & $1(1.2)$ & 0.29 & $\mathrm{NS}$ \\
\hline
\end{tabular}

${ }^{a} p<0.01$ (uncorrected) 
Table 4. Frequencies of HLA-DQB1 alleles in Japanese Type 1 (insulin-dependent) diabetic patients and control subjects

\begin{tabular}{|c|c|c|c|c|c|}
\hline & $\begin{array}{l}\text { Patients } \\
(n=99) \\
n(\%)\end{array}$ & $\begin{array}{l}\text { Control } \\
\text { subjects } \\
(n=86) \\
n(\%)\end{array}$ & $R R$ & $p c$ value & $\begin{array}{l}\text { Serological } \\
\text { specificity }\end{array}$ \\
\hline DQB1*0501(ND) & $6(6.1)$ & $9(10.5)$ & 0.57 & NS & DQw5(w1) \\
\hline DQB1*0502(ND) & $1(1.0)$ & $2(2.3)$ & 0.51 & NS & DQw5(w1) \\
\hline DQB1*0503(D) & $3(3.0)$ & $6(7.0)$ & 0.45 & NS & DQw5(w1) \\
\hline DQB1*0601(D) & $6(6.1)$ & $23(26.7)$ & 0.19 & $<0.01$ & DQw6(w1) \\
\hline DQB1*0602(D) & $1(1.0)$ & $21(24.4)$ & 0.046 & $<0.0001$ & DQw6(w1) \\
\hline DQB1*0603(D) & $0(0)$ & $0(0)$ & - & NS & DQw6(w1) \\
\hline DOB1*0604(ND) & $22(22.2)$ & $11(12.8)$ & 1.9 & NS & DQw6(w1) \\
\hline DQB1*0201(ND) & $1(1.0)$ & $1(1.2)$ & 0.87 & NS & DQw2 \\
\hline DQB1*0301(D) & $2(2.0)$ & $15(17.4)$ & 0.12 & $<0.01$ & DQw7(w3) \\
\hline DQB1*0302(ND) & $26(26.3)$ & $16(18.6)$ & 1.6 & NS & DQw8(w3) \\
\hline DQB1*0303(D) & $51(51.5)$ & $29(33.7)$ & 2.1 & $\mathrm{NS}^{\mathrm{a}}$ & DQw9(w3) \\
\hline DQB1*0401(D) & $52(52.5)$ & $18(20.9)$ & 4.1 & $<0.001$ & DQw4 \\
\hline DQB1*0402(D) & $9(9.1)$ & $4(4.7)$ & 1.9 & NS & DQw4 \\
\hline
\end{tabular}

${ }^{\mathrm{a}} p<0.05$ (uncorrected); (D), Asp-57 allele; (ND), non-Asp-57 allele

Table 5. Frequencies of probable haplotypes in Japanese Type 1 (insulin-dependent) diabetic patients and control subjects

\begin{tabular}{lcclll}
\hline Probable haplotype & $\begin{array}{c}\text { Patients } \\
(n=99) \\
n(\%)\end{array}$ & $\begin{array}{l}\text { Control } \\
\text { subjects } \\
(n=86) \\
n(\%)\end{array}$ & $R R$ & $p c$ value & $\begin{array}{l}\text { Serological } \\
\text { specificity }\end{array}$ \\
\hline DR1-DQA1*0101-DQB1*0501 & $6(6.1)$ & $7(8.1)$ & 0.74 & NS & DR1-DQw5 \\
DR2-DQA1*0102-DQB1*0601 & $0(0)$ & $8(9.3)$ & 0.046 & NS $^{\text {a }}$ & DR2-DQw6 \\
DR2-DQA1*0103-DQB1*0601 & $2(2.0)$ & $5(5.8)$ & 0.38 & NS & DR2-DQw6 \\
DR2-DQA1*0102-DQB1*0602 & $1(1.0)$ & $19(22.1)$ & 0.053 & $<0.0001$ & DR2-DQw6 \\
DRB1*0403-DQA1*0301-DQB1*0302 & $5(5.0)$ & $9(10.5)$ & 0.47 & NS & DR4(Dw13)-DQw8 \\
DRB1*0406-DQA1*0301-DQB1*0302 & $1(1.0)$ & $6(7.0)$ & 0.19 & NS & DR4(DwKT2)-DQw8 \\
DRB1*0405-DQA1*0301-DQB1*0401 & $52(52.5)$ & $17(19.8)$ & 4.4 & $<0.001$ & DR4(Dw15)-DQw4 \\
DR7-DQA1*0201-DQB1*0201 & $1(1.0)$ & $1(1.2)$ & 0.87 & NS & DR7-DQw2 \\
DRw8-DQA1*0102-DQB1*0601 & $3(3.0)$ & $6(7.0)$ & 0.45 & NS & DRw8-DQw6 \\
DRw8-DQA1*0103-DQB1*0601 & $2(2.0)$ & $4(4.7)$ & 0.47 & NS & DRw8-DQw6 \\
DRw8-DQA1*0301-DQB1*0302 & $14(14.1)$ & $1(1.2)$ & 9.7 & <0.05 & DRw8-DQw8 \\
DRw8-DQA1*0401-DQB1*0402 & $7(7.1)$ & $2(2.3)$ & 2.7 & NS & DRw8-DQw4 \\
DR9-DQA1*0301-DQB1*0303 & $51(51.5)$ & $28(32.6)$ & 2.2 & NS & DR9mDQw9 \\
DRw11-DQA1*0501-DQB1*0301 & $0(0)$ & $9(10.5)$ & 0.041 & $<0.05$ & DRw11-DQw7 \\
DRw12-DQA1*0501-DQB1*0301 & $1(1.0)$ & $4(4.7)$ & 0.28 & NS & DRw12-DQw7 \\
DRw13-DQA1*0102-DQB1*0604 & $22(22.2)$ & $11(12.8)$ & 1.9 & NS & DRw13-DQw6 \\
DRw14-DQA1*0101-DQB1*0502 & $1(1.0)$ & $2(2.3)$ & 0.51 & NS & DRw14-DQw5 \\
DRw14-DQA1*0101-DQB1*0503 & $2(2.0)$ & $6(7.0)$ & 0.32 & NS & DRw14-DQw5 \\
\hline
\end{tabular}

${ }^{\mathrm{a}} p<0.01$ (uncorrected); ${ }^{\mathrm{b}} p<0.05$ (uncorrected)

DQw4 and DR9-DQw9, both of which carry Asp-57 DQB1. Therefore, HLA class II genes other than DQB1 may contribute to Type 1 diabetes susceptibility in Japanese. As for DQA1, these haplotypes both carry the DQA1*0301 allele. Todd et al. [16], and recently Yamagata et al. [18], reported that the DQA1*0301 allele was increased in Japanese Type 1 diabetic patients. In this study, we also found that DQA $1 * 0301$ allele is significantly increased in the patients. Moreover, it is known that the DQA $1 * 0301$ allele is positively associated with Type 1 diabetes in Caucasians [12,20], and in Blacks [11,21]. Thus, it is possible that the DQA1*0301 allele itself contributes to Type 1 diabetes susceptibility in Japanese.

In addition, the contribution of DRB 1 is also suggested in this study. In Caucasians, Sheehy et al. [13] reported that DRB1*0401(Dw4) and DRB1*0402(Dw10) on the DR4 haplotype were associated with Type 1 diabetes. DRB1*0401 and DRB1*0402 were not observed in the present study. Instead, DRB $1 * 0405$ was markedly increased in DR4-positive patients and the DR4(Dw15)DQA1*0301-DQB1*0401 haplotype was significantly increased in the patients. In contrast, the DRB $1 * 0406$ DQA $1 * 0301-\mathrm{DQB} 1 * 0302$ haplotype was decreased in the patients, although the DRw8-DQA1*0301-DQB1*0302 haplotype was significantly creased. These data may indicate that the DRB1 gene which determines the DRB1*0405 subtype contributes to DR4-associated susceptibility and that DRB $1 * 0406$ has a protective effect on the DQA $1 * 0301-D Q B 1 * 0302$ haplotype. As DRB1-57 of DRB $1^{*} 0405$ is serine and also that of DR9 is valine [19], it 
Table 6. Observed (Obs.) and expected (Exp.) genotype frequencies in Japanese Type 1 (insulin-dependent) diabetic patients and control subjects

\begin{tabular}{|c|c|c|c|c|c|c|c|}
\hline \multirow[t]{2}{*}{ Genotype } & \multicolumn{3}{|c|}{ Patients } & \multicolumn{3}{|c|}{ Control subjects } & \multirow[t]{2}{*}{$R R$} \\
\hline & Obs. & Exp. & $\chi^{2}$ & Obs. & Exp. & $\chi^{2}$ & \\
\hline [DR4(Dw15)-DQw4]/[DR4(Dw15)-DQw4] & 6 & 9.57 & 1.33 & 1 & 0.94 & 0.00 & 4.0 \\
\hline [DR4(Dw15)-DQw4]/[DRw8-DQw8] & 9 & 4.52 & 4.44 & 0 & 0.11 & 0.11 & 18.2 \\
\hline [DR4(Dw15)-DQw4]/[DR9-DQw9] & 13 & 18.70 & 1.74 & 4 & 3.21 & 0.20 & 2.9 \\
\hline$[\mathrm{DR} 4(\mathrm{Dw} 15)-\mathrm{DQw} 4] /[\mathrm{DRw13-DQw6]}$ & 12 & 7.27 & 3.08 & 1 & 1.19 & 0.03 & 8.1 \\
\hline$[\mathrm{DR} 4(\mathrm{Dw} w 15)-\mathrm{DQw} 4] / \mathrm{X}$ & 14 & 11.94 & 0.36 & 12 & 11.57 & 0.02 & 1.0 \\
\hline [DRw8-DQw8]/[DRw8-DQw8] & 0 & 0.53 & 0.53 & 0 & 0.00 & 0.00 & - \\
\hline [DRw8-DQw8]/[DR9-DQw9] & 5 & 4.41 & 0.08 & 0 & 0.18 & 0.18 & 10.1 \\
\hline [DRw8-DQw8]/[DRw13-DQw6] & 0 & 1.72 & 1.72 & 0 & 0.07 & 0.07 & - \\
\hline [DRw8-DQw8]/X & 0 & 2.82 & 2.82 & 1 & 0.65 & 0.19 & 0.29 \\
\hline [DR9-DQw9]/[DR9-DQw9] & 11 & 9.13 & 0.38 & 4 & 2.75 & 0.57 & 2.4 \\
\hline [DR9-DQw9]/[DRw13-DQw6] & 8 & 7.10 & 0.11 & 1 & 2.03 & 0.53 & 5.3 \\
\hline [DR9-DQw9]/X & 14 & 11.66 & 0.47 & 19 & 19.83 & 0.04 & 0.59 \\
\hline [DRw13-DQw6]/[DRw13-DQw6] & 0 & 1.38 & 1.38 & 0 & 0.38 & 0.38 & - \\
\hline$[\mathrm{DRw13-DQw6]/X}$ & 2 & 4.53 & 1.42 & 9 & 7.34 & 0.38 & 0.21 \\
\hline $\mathrm{X} / \mathrm{X}$ & 5 & 3.72 & 0.44 & 34 & 35.78 & 0.09 & 0.089 \\
\hline Total & 99 & 99.00 & $20.28^{\mathrm{a}}$ & 86 & 86.03 & $2.76^{\mathrm{b}}$ & \\
\hline
\end{tabular}

Expected values were determined with gene frequencies. Gene frequencies were DR4(Dw15)-DOw4 = 0.311 (Type 1), 0.104 (control); DRw8-DQw8 $=0.073$ (Type 1), 0.006 (control); DR9-DQw9 $=0.304$

is possible that non-Asp-57 DRB1 may play an important role in antigen binding and $\mathrm{T}$-cell recognition on the analogy of non-Asp-57 DQB1. However, this hypothesis does not fit in several haplotypes. We found that the DRw8DQw8 haplotype which is positively associated with the disease carries Asp at DRB1-57, and that DRw8-DQw6 haplotype carries serine but is neutrally associated, with 5.50 analysis.

Another possible explanation is based on the peptideaffinity model of HLA class II molecule, recently proposed by Nepom for Caucasian patients [22]. The complicated HLA associations with Type 1 diabetes in Japanese patients may be explained if we assume that a susceptibility class II molecule, such as DQ4(DQA1*0301,DQB1*0401) or DQ3.3(DQA1*0301, DQB1*0303), competes with other class II molecules (e.g. DR) for binding the diabetogenic peptides in each individual. However, this hypothesis requires further studies.

Negative association of the DQB $1 * 0602$ was distinct. DQB1*0602 is also negatively associated with Type 1 diabetes in Caucasians [12, 20] and in Blacks [21], suggesting that $\mathrm{DQB} 1 * 0602$ itself has a strong protective effect. The DQB1*0601 was also negatively associated with the disease. However, the DRw8-DQw6 haplotype, which has no significant association with the disease, also carries DQB1*0601. DQB1*0601 is rare in Caucasians and in Blacks, thus, the protective effect of DQB1*0601 is not as clear as that of DQB1*0602. The DQA1*0501 was negatively associated with Type 1 diabetes in Japanese and was found on the DRw11-DQw7 or DRw12-DQw7 haplotype. However, DQA1*0501 is neutrally associated both in Caucasians [20] and in Blacks [21]. Therefore, the negative association of DQA1*0501 may be secondary to linkage disequilibrium with a primary protective allele.

We also reported here the genotype frequencies of Japanese patients. There was a deviation from the HardyWeinberg equilibrium in Japanese patients. This result
(Type 1), 0.179 (control); DRw13-DQw6=0.118 (Type 1), 0.066 (control); and others (X) $=0.194$ (Type 1), 0.645 (control). ${ }^{\mathrm{a}} p<0.05,{ }^{\mathrm{b}} \mathrm{NS}$

may indicate that some interactions exist between the susceptibility haplotypes. The risk of [DR4(Dw15)DQw4]/[DR9-DQw9] heterozygotes was not increased, and increased risk of heterozygotes was observed in [DR4(Dw15)-DQw4]/[DRw8-DQw8] and [DR4(Dw15)DQw4]/[DRw13-DQw6]. Recently, the increased risk of the DR3/DR4 heterozygotes reported in Caucasians was explained by the formation of a transcomplement molecule between DQA1 and DQB1 molecules [23]. However, distinct transcomplements cannot be formed in the [DR4(Dw15)-DQw4]/[DRw8-DQw8] genotype, because both the haplotypes carry the same DQA1*0301 allele. This may indicate that other genetic factors associated with these haplotypes also contribute to Type 1 diabetes in Japanese.

Acknowledgements. We are grateful to Dr. T.Juji and Dr. S. Amemiya for providing us with blood samples from their subjects. This work is partially supported by grants from the Ministry of Education, Science and Culture, Government of Japan, and a grant from the Ministry of Health and Welfare, Government of Japan.

\section{References}

1. Eisenbarth GS (1986) Type 1 diabetes mellitus. A chronic autoimmune disease. N Engl J Med 314: 1360-1368

2. Tiwari JL, Terasaki PI (1985) Juvenile diabetes mellitus (insulindependent). In: Tiwari JL, Terasaki PI (eds) HLA and disease associations. Springer, Berlin Heidelberg New York, pp 185-210

3. Thomson G, Robinson WP, Kuhner MK et al. (1988) Genetic heterogeneity, modes of inheritance, and risk estimates for a joint study of Caucasians with insulin-dependent diabetes mellitus. Am J Hum Genet 43:799-816

4. Matsuda A, Kuzuya T, Iwamoto Y et al. (1988) HLA DR antigens in adult-onset and juvenile-onset Japanese insulin-dependent diabetic patients. Diab Res Clin Pract 5: 107-112

5. Aparicio JMR, Wakisaka A, Takeda A, Matsuura N, Aizawa M (1988) HLA-DQ system and insulin-dependent diabetes mellitus in Japanese: does it contribute to the development of IDDM as it does in Caucasians? Immunogenetics 28: 240-246 
6. Mimura G, Kida K, Matsuura N et al. (1990) Immunogenetics of early-onset insulin-dependent diabetes mellitus among the Japanese: HLA, Gm, BF, GLO, and organ-specific autoantibodies - the J.D.S. study. Diab Res Clin Pract 8: 253-262

7. Todd JA, Bell JI, McDevitt HO (1987) HLA-DQ $\beta$ gene contributes to susceptibility and resistance to insulin-dependent diabetes mellitus. Nature 329: 599-604

8. Horn GT, Bugawan TL, Long CM, Erlich HA (1988) Allelic sequence variation of the HLA-DQ loci: relationship to serology and to insulin-dependent diabetes susceptibility. Proc Natl Acad Sci USA 85: 6012-6016

9. Morel PA, Dorman JS, Todd JA, McDevitt HO, Trucco M (1988) Aspartic acid at position 57 of the HLA-DQ $\beta$ chain protects against type 1 diabetes: a family study. Proc Natl Acad Sci USA 85: 8111-8115

10. Brown JH, Jardetzky T, Saper MA, Samraoui B, Bjorkman PJ, Wiley DC (1988) A hypothetical model of the foreign antigen binding site of class II histocompatibility molecules. Nature 332: $845-850$

11. Todd JA, Mijovic C, Fletcher J, Jenkins D, Bradwell AR, Barnett AH (1989) Identification of susceptibility loci for insulin-dependent diabetes mellitus by trans-racial gene mapping. Nature 338: $587-589$

12. Khalil I, d'Auriol L, Gobet $M$ et al. (1990) A combination of HLA-DQ $\beta$ Asp57 negative and HLA-DQ $\alpha$ Arg52 confers susceptibility to insulin-dependent diabetes mellitus. J Clin Invest 85: 1315-1319

13. Sheehy MJ, Scharf SJ, Rowe JR et al. (1989) A diabetes-susceptible HLA haplotype is best defined by a combination of HLADR and -DQ alleles. J Clin Invest 83: 830-835

14. Awata T, Kuzuya T, Matsuda A et al. (1990) High frequency of aspartic acid at position 57 of HLA-DQ $\beta$-chain in Japanese IDDM patients and nondiabetic subjects. Diabetes 39: 266-269

15. Lundin KEA, Rønningen KS, Aono S et al. (1989) HLA-DQ antigens and DQ $\beta$ amino acid 57 of Japanese patients with insulin-dependent diabetes mellitus: detection of a DRw8DQw8 haplotype. Tissue Antigens 34: 233-241

16. Todd JA, Fukui Y, Kitagawa T, Sasazuki T (1990) The A3 allele of the HLA-DQA1 locus is associated with susceptibility to type 1 diabetes in Japanese. Proc Natl Acad Sci USA 87: 1094 1098

17. Ikegami H, Tahara Y, Cha T et al. (1990) Aspartic acid at position 57 of the HLA-DQ $\beta$ chain is not protective against insulindependent diabetes mellitus in Japanese people. J Autoimmunity 3: 167-174

18. Yamagata K, Hanafusa T, Nakajima H et al. (1991) HLADQA1*1 contributes to resistance and A $1 * 3$ confers susceptibility to Type 1 (insulin-dependent) diabetes mellitus in Japanese subjects. Diabetologia 34: 133-136

19. Knowles RW (1989) Structural polymorphism of the HLA class II $\alpha$ and $\beta$ chains: summary of the 10 th workshop 2-D gel analysis. In: Dupont B (ed) Immunology of HLA, Vol 1 (Histocompatibility testing 1987). Springer, New York, pp 365-380

20. Rønningen KS, Spurkland A, Iwe T, Vartdel F, Thorsby E (1991) Distribution of HLA-DRB1, -DQA1 and DQB1 alleles and DQA1-DQB1 genotypes among Norwegian patients with insulin-dependent diabetes mellitus. Tissue Antigens 37: 105-111

21. Mijovic CH, Jenkins P, Jacobs KH, Penny MA, Fletcher JA, Barnett AH (1991) HLA-DQA1 and -DQB1 alleles associated with genetic susceptibility to IDDM in a black population. Diabetes 40: $748-753$

22. Nepom GT (1990) A unified hypothesis for the complex genetics of HLA associations with IDDM. Diabetes 39: 1153-1157

23. Nepom BS, Schwarz D, Palmer JP, Nepom GT (1987) Transcomplementation of HLA genes in IDDM. HLA-DQ $\alpha$ - and $\beta$ chains produce hybrid molecules in DR3/4 heterozygotes. Diabetes 36: 114-117

Received: 9 August 1991

and in final revised form:9 December 1991

Dr. T. Awata

Division of Endocrinology and Metabolism

Jichi Medical School

Minamikawachi-machi

Kawachi-gun

Tochigi-ken, 329-04

Japan 